\title{
Persistent cerebrospinal fluid-cutaneous fistula after epidural analgesia: a case report and review of literature
}

\author{
Andrea Tsai' ${ }^{1}$ Shihab Ahmed ${ }^{2}$ and Jingping Wang ${ }^{2^{*}}$ \\ *Correspondence: jwang23@partners.org

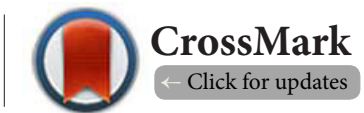 \\ 'Department of Anesthesia, Critical Care and Pain Medicine, Massachusetts General Hospital, Clinical Fellow, Harvard Medical School, \\ Boston, MA, USA. \\ ${ }^{2}$ Department of Anesthesia, Critical Care and Pain Medicine, Assistant Professor Massachusetts General Hospital, Boston, MA, USA.
}

\begin{abstract}
Presented is a case of persistent high-output cerebrospinal fluid (CSF) leak following epidural catheter removal on postoperative day 5 for a 64-year-old patient after exploratory laparotomy. Epidural catheter placement required multiple attempts preoperatively and was complicated by a "wet tap". Diagnosis of CSF leak was made with glucose, protein and beta-2 transferrin testing. In our review of 30 cases with reported CSF-cutaneous fistula, a trend towards requiring epidural blood patch for symptom relief exists when larger bore needles are used (all 9 reports involving 14 gauge or larger needles and 2 reports of fistulas resulting from a surgical defect) and duration of catheter stay is long. Notably, there were 3 case reports of CSF-cutaneous fistulas occurring without the placement of a catheter. Among 9 cases of fistula reported in the obstetric population, only one patient needed EBP for symptom control. Location of the needle/catheter insertion site at different levels of the neuraxium does not appear to affect the risk of developing a CSF-cutaneous fistula. CSF-cutaneous fistulas are a rare event that should be recognized early due to the potential for infections and neurologic complications. Glucose and protein testing offer a rapid but less specific means of diagnosing a possible CSF leak and can be used as guidance while awaiting results from beta-2 transferrin or beta-trace protein testing for definitive identification of CSF. With literature review, we propose an algorithm to help early detection and management of CSF-cutaneous fistula.
\end{abstract}

Keywords: Epidural analgesia, cerebrospinal fluid-cutaneous fistula, beta-2 transferrin, postoperative pain management

\section{Introduction}

Cerebrospinal fluid (CSF)-cutaneous fistulas are a rare complication of procedures accessing the neuraxium. As such, recognition of this complication may be delayed, and optimal management is unclear. We present a case of an asymptomatic but high-output and prolonged CSF-cutaneous fistula following epidural analgesia for postoperative pain management, as well as a review of the CSF-cutaneous fistula literature. Our patient was managed successfully with conservative measures and an algorithm is proposed to help in early detection and management of CSF-cutaneous fistulas.

\section{Case presentation}

A 64-year-old Caucasian female presented with a high-output enterocutaneous fistula and increased herniation of the bowel. The patient had undergone extensive abdominal resection for stage IIIC serous papillary ovarian adenocarcinoma which was complicated by wound dehiscence treated with vacuumassisted closure. She subsequently underwent multiple rounds of chemotherapy. On day of surgery, she underwent exploratory laparotomy, lysis of adhesions, takedown of enterocutaneous fistula, small bowel resection, and repair of large incisional hernia using biological mesh (SurgiMend).
Preoperatively, a lumbar epidural catheter was placed for postoperative pain management. Three attempts were made prior to successful epidural placement, each with a 17 gauge Tuohy needle. In the first attempt, the L2-L3 epidural space was found using the loss of resistance technique, but the epidural catheter was unable to be threaded. In the second attempt, the L2-L3 epidural space was again found using the same loss of resistance technique. A Portex epidural catheter was placed, but clear fluid was noted on aspiration and the catheter was removed. The final attempt was successfully completed by a different anesthesiologist at the L1-L2 space and an Arrow epidural catheter was placed with negative aspiration and a negative test dose.

The patient's initial postoperative course was uncomplicated. She was admitted to the surgical intensive care unit (ICU) for close respiratory and hemodynamic monitoring. Upon admission to the ICU, her epidural provided right greater than left sided coverage and required boluses of $5 \mathrm{cc}$ of $0.25 \%$ bupivicaine followed by $5 \mathrm{cc}$ of $0.5 \%$ bupivicaine. This resulted in transient leg numbness which resolved spontaneously. Her epidural infusion was started with bupivicaine $0.1 \%$ at $12 \mathrm{ml} /$ hour in addition to an IV hydromorphone patient-controlled analgesia (PCA) $(0.4 \mathrm{mg}$ demand dose, 10 minute lockout, no 
Tsai et al. Journal of Anesthesiology \& Clinical Science 2014,

continuous rate, $2.5 \mathrm{mg} 1$ hour maximum).

On postoperative day 2 , the patient was transferred to the floor and continued on the same pain regimen. Though coverage continued to be greater on the right side, the patient reported adequate pain control without neurologic deficits.

On postoperative day 5, the epidural was removed with tip intact per acute pain service protocol. Pain control was achieved with the continuation of the patient's hydromorphone PCA alone at the same settings. Following epidural removal, it was noted that clear fluid was draining from the insertion site. The site was covered with sterile $4 \times 4$ gauze and abdominal pads held in place by the patient's abdominal binder. The patient was afebrile, with stable vitals and denied the occurrence of headache, nuchal pain or rigidity, diplopia or other visual or neurologic disturbances.

On postoperative day 6, clear fluid continued to drain from the epidural insertion site, requiring five dressing changes in the course of 24 hours. Two vials of this fluid were collected for analysis; it took approximately 3 minutes to collect 1 $\mathrm{ml}$ of fluid. Both vials were sent to the lab for glucose and total protein analysis; the second was also sent for beta- 2 transferrin analysis. The glucose and protein levels in vial 1 were $84 \mathrm{mg} / \mathrm{dl}$ and $0 \mathrm{~g} / \mathrm{dl}$ and $80 \mathrm{mg} / \mathrm{dl}$ and $0.1 \mathrm{~g} / \mathrm{dl}$ in vial 2 (the patient's plasma glucose at that time was $117 \mathrm{mg} /$ dl). On postoperative day 8 , beta- 2 transferrin was detected from the initial samples of fluid, suggesting CSF leakage. The patient continued to be asymptomatic from a neurologic standpoint and continued clear fluid continued to leak at the same rate from the epidural insertion site. After discussion with the surgical team, a single figure of eight cutaneous stitch was sterilely placed to close the epidural insertion site, and the patient was placed on empiric prophylactic antibiotics: metronidazole, cefepime and vancomycin. The patient remained asymptomatic and after a 4 day course, the antibiotics were discontinued. Beginning on the operative day, the patient had been on anticoagulation with heparin 5000 units SC BID for routine venous thromboembolism prophylaxis; however, on postoperative day 6 , the patient had started treatment with dalteparin for possible pulmonary embolism, limiting our ability to consider epidural blood patching (EBP). Due to ongoing problems with fluid overload, the patient was unable to tolerate recumbent positioning required for further imaging. On continued evaluation, the epidural insertion site remained benign appearing with no further discharge following placement of the cutaneous stitch and the patient continued to remain afebrile with no neurologic symptoms. The patient was converted to an oral regimen of hydromorphone $2-4 \mathrm{mg}$ PO Q4HPRN starting postoperative day 12 . On postoperative day 14 , she was discharged to home with no sequelae.

\section{Discussion}

Although a rare complication of neuraxial procedures, there have been multiple case reports of CSF-cutaneous fistulas.
They have occurred following spinal surgery [1-2], long- and short-term intrathecal catheters [3-11], diagnostic and therapeutic lumbar punctures [12], combined spinal and epidurals (CSE) [13], epidural catheters [14-20], and one-shot epidural anesthetics and steroid injections [21-23]. An overview of CSF-cutaneous fistula reports is presented in Table 1.

In our review of 30 cases with reported CSF-cutaneous fistula, a trend towards requiring EBP for symptom relief exists when larger bore needles are used (all 9 reports involving 14 gauge or larger needles and 2 reports of fistulas resulting from a surgical defect) and duration of catheter stay is long. Notably, there were 3 case reports of CSF-cutaneous fistulas occurring without the placement of a catheter. Among 9 cases of fistula reported in the obstetric population, only one patient needed EBP for symptom control. We do not have a clear explanation for this observation. Location of the needle/catheter insertion site at different levels of the neuraxium does not appear to affect the risk of developing a CSF-cutaneous fistula.

The risk factors hypothesized to contribute to the deveopment of a CSF-cutaneous fistula include steroid use (systemic

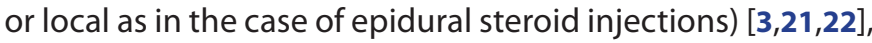
accessing the neuraxium through post-laminectomy scar tissue that may have impaired healing ability $[5,21]$, multiple passes at the same level particularly if using the same needle (even without clear evidence of a "wet tap") [14,21,23], and duration of subarachnoid drainage and catheter size (in the case of intrathecal catheters) $[4,7,12]$. It has been suggested that all of these factors might interfere with the healing of a CSF-cutaneous tract. Steroids have a known suppressive effect on wound healing. It has been put forward that multiple passes in the same level with the same needle may lead to fibrin deposition along the tract that may interfere with tract closure $[14,23]$. If multiple passes are required, it is recommended that the needle be thoroughly cleaned in between passes, a new needle be used, or different levels be attempted $[21,23]$. In the case of our patient, the multiple attempts at epidural placement, particularly with the history of a "wet tap" may have increased her risk for the development of this fistula.

It is not uncommon for drainage to occur following the removal of an epidural catheter; however, drainage is usually attributed to subcutaneous edema or local anesthetic rather than CSF. It may be that the incidence of CSF leak is underdiagnosed and in fact higher than currently recognized. Given that a delay in management may lead to the development of symptoms of intracranial hypotension or even more serious complications such as subdural hematoma [11] or meningitis $[\mathbf{1 8 , 2 2}]$, this is an important entity to be recognized. In neurosurgical/ENT literature, CSF rhinorrhea/otorrhea is commonly diagnosed by testing for the presence of beta2 transferrin $[\mathbf{1 3}, \mathbf{2 4}]$ or beta-trace protein $[24]$ in the fluid. Although the beta-2 transferrin assay is highly sensitive and specific for CSF, it can be a time consuming assay. Rapid but less specific tests for CSF that may be useful in these situations 
Tsai et al. Journal of Anesthesiology \& Clinical Science 2014,

http://www.hoajonline.com/journals/pdf/2049-9752-3-2.pdf

Table 1. CSF-cutaneous fistula literature: summary of reports and diagnostic and treatment approaches.

\begin{tabular}{|c|c|c|c|c|c|c|c|c|c|}
\hline Reference & Inciting Event & $\begin{array}{l}\text { Needle/Catheter } \\
\text { Size }\end{array}$ & $\begin{array}{l}\text { Multiple } \\
\text { attempt? }\end{array}$ & $\begin{array}{l}\text { Duration } \\
\text { of catheter } \\
\text { stay (day) }\end{array}$ & $\begin{array}{l}\text { Diagnostic } \\
\text { testing }\end{array}$ & Antibiotics & PDPH & EBP & $\begin{array}{l}\text { Cutaneous } \\
\text { stitch }\end{array}$ \\
\hline [23] & Epidural (labor) & INAA & Yes & 0 & Yes & None & Yes & No & No \\
\hline$[10]$ & IT catheter (labor) & INAA & No & INAA & None & None & Yes & No & No \\
\hline$[5]$ & $\begin{array}{l}\text { IT catheter (surgical } \\
\text { anesthesia) }\end{array}$ & $17 \mathrm{G} / 20 \mathrm{G}$ & No & $<1$ & Yes & None & Yes & No & Yes \\
\hline [6] & $\begin{array}{l}\text { IT catheter baclofen } \\
\text { pump }\end{array}$ & $14 \mathrm{G} / 1.6 \mathrm{~mm}$ & No & 8 & None & None & No & Yes & No \\
\hline [7] & $\begin{array}{l}\text { IT catheter baclofen } \\
\text { pump }\end{array}$ & $14 \mathrm{G}$ & INAA & 30 & None & None & None & Yes & No \\
\hline [3] & Lumbar drain & $14 \mathrm{G}$ & INAA & 5 & No & None & $\mathrm{PDPH}$ & Yes & No \\
\hline$[4]$ & Lumbar drain & $14 \mathrm{G} / 16 \mathrm{G}$ & INAA & 3 & Yes & None & No & Yes & No \\
\hline$[4]$ & Lumbar drain & $14 \mathrm{G} / 16 \mathrm{G}$ & INAA & 9 & Yes & None & No & Yes & Yes \\
\hline [11] & Lumbar drain & INAA & No & 3 & No & None & Yes & Yes & No \\
\hline$[8]$ & IT catheter pain pump & INAA & INAA & INAA & INAA & INAA & INAA & Yes & No \\
\hline [7] & Lumbar shunt & INAA & INAA & 125 & No & None & Yes & Yes & No \\
\hline [9] & Omaya reservoir & $2.1 \mathrm{~mm}$ & Yes & 28 & No & None & No & Yes & Yes \\
\hline$[21]$ & $\begin{array}{l}\text { Epidural steroid } \\
\text { injection }\end{array}$ & INAA & Yes & 0 & Yes & Yes & Yes & Yes & Yes \\
\hline$[22]$ & $\begin{array}{l}\text { Epidural steroid } \\
\text { injection }\end{array}$ & $17 \mathrm{G}$ & Yes & 0 & no & Yes & No & Yes & No \\
\hline$[12]$ & $\begin{array}{l}\text { Lumbar punctures for } \\
\text { chemotherapy }\end{array}$ & $22 \mathrm{G}$ & yes & 0 & no & None & no & yes & No \\
\hline [2] & laminectomy & INAA & INAA & 0 & Yes & INAA & Yes & Yes & No \\
\hline [1] & laminectomy & INAA & INAA & 0 & INAA & INAA & yes & yes & No \\
\hline
\end{tabular}

are glucose and protein analysis. Presence of glucose in the leaking fluid would suggest against a leak of epidural medication. Interstitial fluid generally has a one to two order of magnitude greater protein concentration compared to CSF $[25,26]$, therefore a protein concentration $\geq 1 \mathrm{~g} / \mathrm{dl}$ would be more suggestive of interstitial fluid leakage and has been used to rule out CSF leakage from epidural sites in the past $[\mathbf{2 5 , 2 7 ]}$.

As the incidence of CSF-cutaneous fistulas is rare, treatment for this complication varies widely and optimal management is unclear. Treatment options have included more conservative measures such as sterile dressings $[6,11,19,20,23]$, fluids, and bed rest in positions to minimize CSF pressure on the presumed dural defect as well as minimize dural traction: lateral decubitus +/- hip flexion, prone $+/$ - a pillow under the abdomen, slight trendelenberg $[2,4-6,18,21,23]$. Dehydration and glycerol have been trialed [21], presumably to decrease CSF pressure and therefore promote fistulous tract healing. Cutaneous stitching of the outflow defect has been used $[4,5,13,21]$. Epidural blood patches have been reported to be successful $[\mathbf{3}, \mathbf{4}, \mathbf{6 - 9}, \mathbf{1 1}, \mathbf{1 2}, \mathbf{1 4}, \mathbf{1 6}, \mathbf{2 0}, \mathbf{2 1}]$ even in cases of fistulas due to surgical defects $[1,2]$. Subcutaneous infiltration around the fistula with saline has been suggested [4]. And finally, more invasive solutions such as use of fibrin glue, tract scarification and surgical correction have also been reported $[\mathbf{2 , 9 , 2 2}]$. These treatments have been used alone and also in combination.

Our patient was managed successfully with the placement of a cutaneous suture. Presumably, the placement of a suture halts the loss of CSF, and the accumulating CSF in either the epidural or subcutaneous space resulted in a tamponade that stopped further flow from the dural defect, allowing for closure and healing. Despite the large volume of CSF loss (if the approximately $1 \mathrm{cc}$ per 3 minutes collected from puncture site was $100 \%$ CSF, that would translate to a CSF leak rate of $480 \mathrm{cc}$ daily, close to the total daily production of CSF in the average adult), our patient was asymptomatic. Had symptoms occurred, there would have been a lower threshold to hold anticoagulation and attempt epidural blood patching. We would suggest that in the absence of symptoms, a simple sterile cutaneous stitch to prevent external communication with the neuraxium may be all that is required in terms of treatment.

The role of antibiotics is unclear. Some reports start empiric antibiotic coverage once a fistulous tract is recognized [20,21]; others forego antibiotics in the afebrile, nontoxic patient $[5,23]$. One paper suggests the consideration of antibiotics more strongly in the immunocompromised [18], as there have been reports of these fistulous tracts being further complicated by the development of meningitis. Given the 


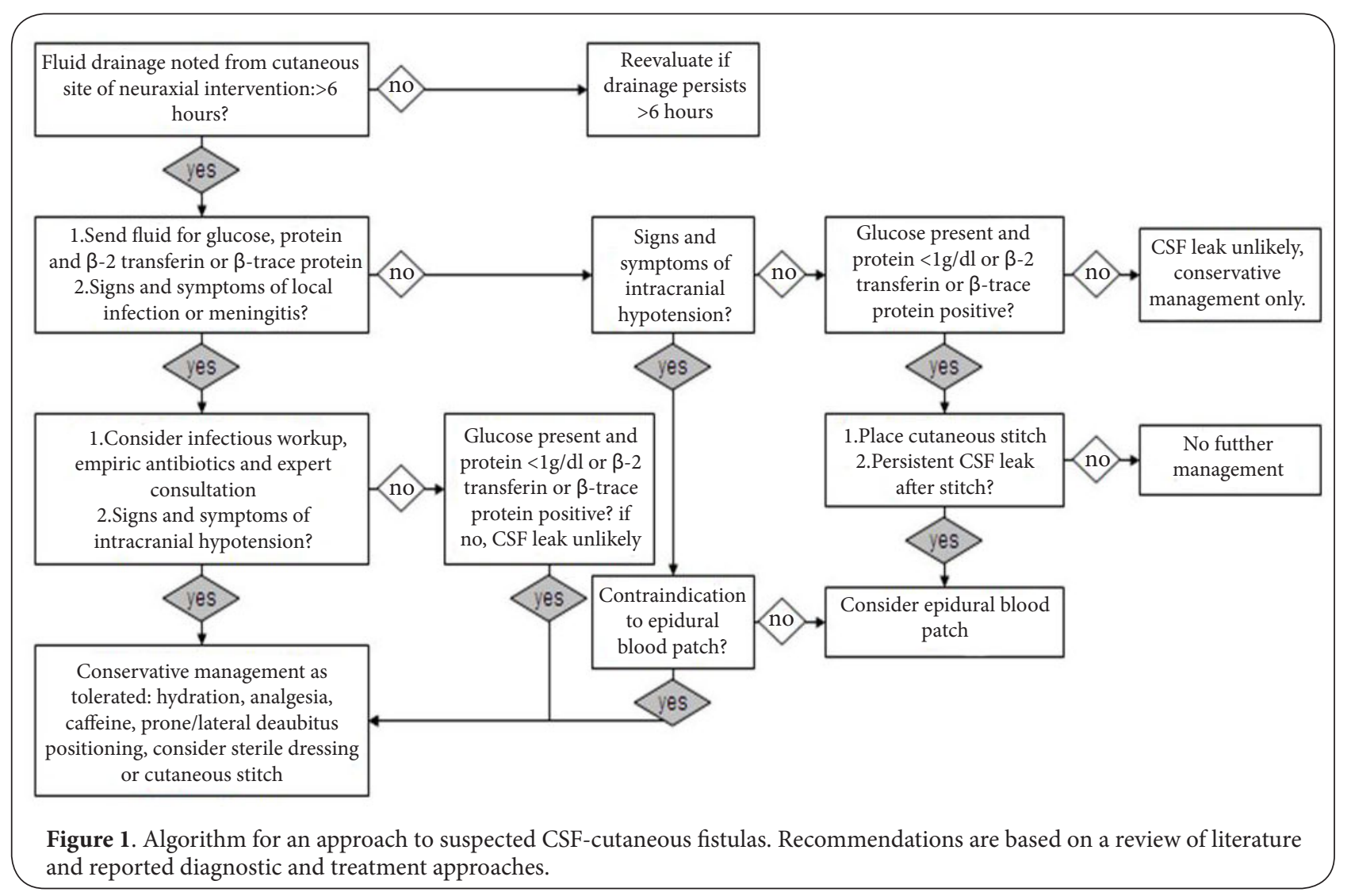

multiple reports of CSF-cutaneous fistulas being treated in the absence of antibiotics with no infectious complications, we would suggest that antibiotics may not be necessary in the afebrile, nontoxic patient. However, these patients merit a low threshold of suspicion for the initiation of antibiotics should signs and symptoms of localized infection/meningitis appear. A possible algorithm for an approach to suspected CSF-cutaneous fistulas is presented in Figure 1.

\section{Conclusion}

CSF-cutaneous fistulas are a rare event that should be recognized early due to the potential for infections and neurologic complications. Glucose and protein testing offer a rapid but less specific means of diagnosing a possible CSF leak and can be used as guidance while awaiting results from beta-2 transferrin or beta-trace protein testing for definitive identification of CSF. Patients who are asymptomatic or contraindicated for invasive procedures may be successfully treated with conservative measures, including cutaneous stitching, alone. Otherwise, epidural blood patching has proved to be an effective technique for the management of these fistulas.

\section{Competing interests}

The authors declare that they have no competing interests.
Authors' contributions

\begin{tabular}{|l|c|c|c|}
\hline Authors' contributions & AT & SA & JW \\
\hline Research concept and design & -- & -- & $\checkmark$ \\
\hline Collection and/or assembly of data & $\checkmark$ & -- & -- \\
\hline Data analysis and interpretation & -- & $\checkmark$ & $\checkmark$ \\
\hline Writing the article & $\checkmark$ & $\checkmark$ & $\checkmark$ \\
\hline Critical revision of the article & -- & $\checkmark$ & $\checkmark$ \\
\hline Final approval of article & -- & -- & $\checkmark$ \\
\hline Statistical analysis & -- & $\checkmark$ & -- \\
\hline
\end{tabular}

\section{Acknowledgement}

We would like to thank Katharine Koury, BA for her support in preparing the manuscript.

\section{Publication history}

Editor: Gerald A. Bushman, Childrens Hospital Los Angeles, USA. EIC: D. John Doyle, Case Western Reserve University, USA.

Received: 31-Jan-2014 Revised: 24-Feb-2014

Accepted: 01-Mar-2014 Published: 06-Mar-2014

\section{References}

1. Lauer KK and Haddox JD. Epidural blood patch as treatment for a surgical durocutaneous fistula. J Clin Anesth. 1992; 4:45-7. | Article | PubMed

2. Maycock NF, van Essen J and Pfitzner J. Post-laminectomy cerebrospinal 
fluid fistula treated with epidural blood patch. Spine (Phila Pa 1976). 1994; 19:2223-5. | Article | PubMed

3. Katz J. Treatment of a subarachnoid-cutaneous fistula with an epidural blood patch. Anesthesiology. 1984; 60:603-4. | Article | PubMed

4. Kumar V, Maves T and Barcellos W. Epidural blood patch for treatment of subarachnoid fistula in children. Anaesthesia. 1991; 46:117-8. | Article I PubMed

5. Hullander $M$ and Leivers D. Spinal cutaneous fistula following continuous spinal anesthesia. Anesthesiology. 1992; 76:139-40. | Article I PubMed

6. Hardy PA. Extradural blood patch of a cerebrospinal fluid cutaneous fistula in the presence of an intrathecal drug delivery system. Anesthesiology. 1994; 81:1299-300. | Article | PubMed

7. Chauhan C, Francis GA and Kemeny AA. The avoidance of surgery in the treatment of subarachnoid cutaneous fistula by the use of an epidural blood patch: technical case report. Neurosurgery. 1995; 36:612-3. | Article I PubMed

8. Huch K, Kunz U, Kluger P and Puhl W. Epidural blood patch under fluoroscopic control: non-surgical treatment of lumbar cerebrospinal fluid fistula following implantation of an intrathecal pump system. Spinal Cord. 1999; 37:648-52. | Article | PubMed

9. Sanders JC, Gandhoke R and Moro M. Lumbar epidural blood patch to treat a large, symptomatic postsurgical cerebrospinal fluid leak of 5 weeks duration in a 3-year-old. Anesth Analg. 2004; 98:629-31. | Article | PubMed

10. Steel AG, Watson BJ, Abdy S and Allen JG. Persistent cerebrospinal fluid leak. Anesth Analg. 2004; 99:1266-7. | Article | PubMed

11. Cohen S, Shorshtein A, de La Calzada M, Hunter CW and Solina A. Subarachnoid-cutaneous fistula and subdural hematoma complicating cerebrospinal fluid drainage for thoracoabdominal aorta aneurysm repair. J Clin Anesth. 2006; 18:475-6. | Article | PubMed

12. Kowbel MA and Comfort VK. Caudal epidural blood patch for the treatment of a paediatric subarachnoid-cutaneous fistula. Can J Anaesth. 1995; 42:625-7. | Article | PubMed

13. Chan BO and Paech MJ. Persistent cerebrospinal fluid leak: a complication of the combined spinal-epidural technique. Anesth Analg. 2004; 98:828-30. | Article | PubMed

14. Longmire $\mathrm{S}$ and Joyce $\mathrm{TH}$, 3rd. Treatment of a duro-cutaneous fistula secondary to attempted epidural anesthesia with an epidural autologous blood patch. Anesthesiology. 1984; 60:63-4. | Article | PubMed

15. Motsch J and Hutschenreuter K. [Cutaneous cerebrospinal fluid fistula associated with secondary puncture of the dura caused by a peridural catheter]. Reg Anaesth. 1984; 7:74-6. | PubMed

16. Howes J and Lenz R. Cerebrospinal fluid cutaneous fistula. An unusual complication of epidural anaesthesia. Anaesthesia. 1994; 49:221-2. | Article | PubMed

17. Joseph $D$ and Anwari JS. Cerebrospinal fluid cutaneous fistula after labour epidural analgesia. Middle East J Anesthesiol. 2001; 16:223-30. | PubMed

18. Abaza KT and Bogod DG. Cerebrospinal fluid-cutaneous fistula and pseudomonas meningitis complicating thoracic epidural analgesia. $\mathrm{Br} J$ Anaesth. 2004; 92:429-31. | Article | PubMed

19. Ayad S, Narouze $S$ and Tetzlaff JE. Possible asymptomatic cerebrospinal fluid leak following successful labour epidural catheter placement. Can J Anaesth. 2004; 51:518-9. | Article | PubMed

20. Hosu L, Meyer MJ and Goldschneider KR. Cerebrospinal fluid cutaneous fistula after epidural analgesia in a child. Reg Anesth Pain Med. 2008; 33:74-6. | Article | PubMed

21. Ball CG, D'Alessandro FT, Rosenthal J and Duff TA. Case history number 86: an unusual complication of lumbar puncture: a CSF cutaneous fistula. Anesth Analg. 1975; 54:691-4. | Article | PubMed

22. Dougherty JH, Jr. and Fraser RA. Complications following intraspinal injections of steroids. Report of two cases. J Neurosurg. 1978; 48:10235. | Article | PubMed
23. Jawalekar SR and Marx GF. Cutaneous cerebrospinal fluid leakage following attempted extradural block. Anesthesiology. 1981; 54:348-9. | Article I PubMed

24. McArthur J, Hill J, Paech MJ, Dodd PH, Bennett EJ and Holden J. Cerebrospinal fluid and serum concentrations of beta-trace protein during pregnancy. Anaesthesia. 2005; 60:163-7. | Article | PubMed

25. Downey L, Slater EM and Zeitlin GL. Differentiating interstitial fluid from cerebral spinal fluid. Anesthesiology. 1985; 63:120. | Article | PubMed

26. Fogh-Andersen N, Altura BM, Altura BT and Siggaard-Andersen O. Composition of interstitial fluid. Clin Chem. 1995; 41:1522-5. | Article | PubMed

27. Bansal S. Fluid leak from epidural puncture site: a diagnostic dilemma. Anesth Analg. 2004; 99:1577; author reply 1577. | Article | PubMed

\section{Citation:}

Tsai A, Ahmed S and Wang J. Persistent cerebrospinal fluid-cutaneous fistula after epidural analgesia: a case report and review of literature. J Anesthesiol Clin Sci. 2014; 3:2. http://dx.doi.org/10.7243/2049-9752-3-2 